\title{
Cadmium may be a risk factor for osteoporosis
}

\author{
Lars Järup, Tobias Alfvén, Bodil Persson, Göran Toss, Carl Gustaf Elinder
}

Department of Environmental Health, Stockholm County Council, and Institute of Environmental Medicine, Karolinska Institute, Sweden L Järup

Karolinska Institute, Stockholm, Sweden T Alfvén

Department of Occupational and Environmental Medicine, Linköping University Hospital, Linköping, Sweden B Persson

Department of Medicine, Linköping University Hospital, Linköping, Sweden G Toss

Department of Renal Medicine at the Karolinska Institute, Huddinge University Hospital, Huddinge, Sweden

C G Elinder

Correspondence to: Dr L Jarup, Department of Environmental Health, Stockholm County Council, Box 1186, S-172 24 Sundbyberg, Sweden.

Accepted 11 February 1998

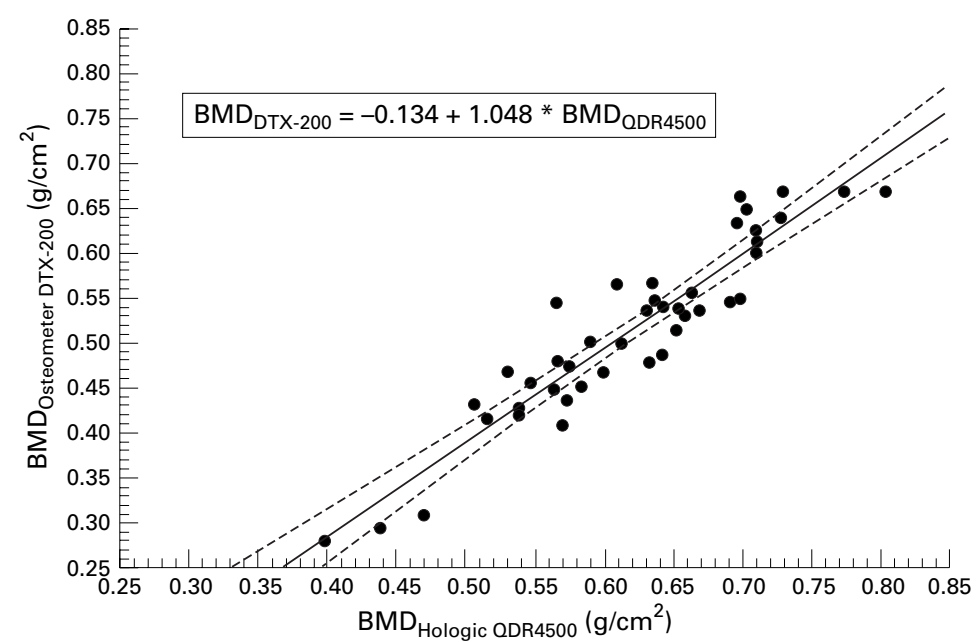

Figure 1 Forearm bone mineral density (BMD) in solderers exposed to cadmium, measured by a movable instrument (Osteometer DTX-200) as a function of forearm BMD measured by a hospital based instrument (Hologic QDR 4500). validate the BMD data obtained with a movable instrument.

Methods-43 workers who were exposed to cadmium for $\leqslant 5$ years before 1978 were studied. Cadmium in blood (B-Cd) and urine (U-Cd) were used as dose estimates. The BMD was assessed in the forearm, the spine, and the hip (neck and trochanter) with a dual energy $x$ ray absorptiometry (DXA) instrument. Age and sex matched reference populations were used to compute $\mathrm{Z}$ scores, commonly used to assess osteoporosis.

Results-The mean forearm $Z$ score was -0.60 (95\% confidence interval (95\% CI) -1.08 to -0.12$)$ in the group exposed to cadmium. The mean $\mathrm{Z}$ score for the spine was $-0.47(95 \% \mathrm{CI}-0.92$ to -0.03$)$, for the hip neck $-0.40(95 \%$ CI -0.75 to -0.05$)$, and for the hip trochanter -0.22 (95\% CI -0.52 to -0.07$)$. The decrease in forearm BMD was correlated with age $(p=0.002)$ and B-Cd $(p=0.040)$. No such correlations were found for the other sites. Workers with tubular proteinuria had a lower fore$\operatorname{arm}$ BMD $(p=0.029)$ and a lower $Z$ score $(p=0.072)$ than workers without tubular proteinuria.

Conclusions-There was a suggested dose-effect relation between cadmium dose and bone mineral density. Furthermore, there was a dose-response relation between cadmium dose and osteoporosis. Cadmium may be a risk factor for the development of osteoporosis at lower doses than previously anticipated.

(Occup Environ Med 1998;55:435-439)

Keywords: cadmium; bone mineral density; osteoporosis

\section{Subjects and methods \\ SUBJECTS}

In 1993, 46 workers exposed to cadmium at a plant that manufactured heat exchangers and coolers took part in an investigation to study the glomerular filtration rate $^{8}$ and the association between blood cadmium as a dose estimate and different markers of tubular proteinuria $\left(\beta_{2}\right.$-microglobulin, protein $\mathrm{HC}\left(\alpha_{1}{ }^{-}\right.$ microglobulin) and N-acetyl- $\beta-\mathrm{D}-$ glucosaminidase (NAG)). ${ }^{9}$ The workers had been exposed to cadmium for $\leqslant 5$ years before 1978 , when soldering material containing cadmium was abandoned. We invited these 46 workers to take part in the present investigation of the skeleton, and 43 of them ( 41 men and two women) agreed to participate.

\section{METHODS}

Cadmium in blood (B-Cd) was determined with inductively coupled plasma mass spectrometry (ICP-MS, Fisons VG Plasmaquad PQ2) at the Department of Occupational and Environmental Medicine at the University 


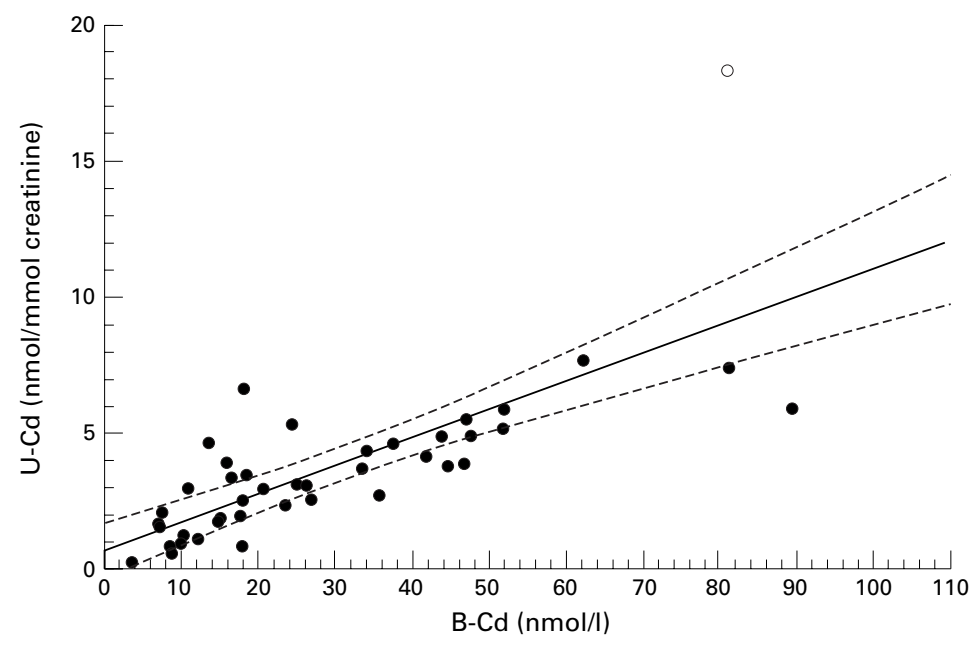

Figure 2 Urinary cadmium measured in 1993 as a function of B-Cd measured in 1996.

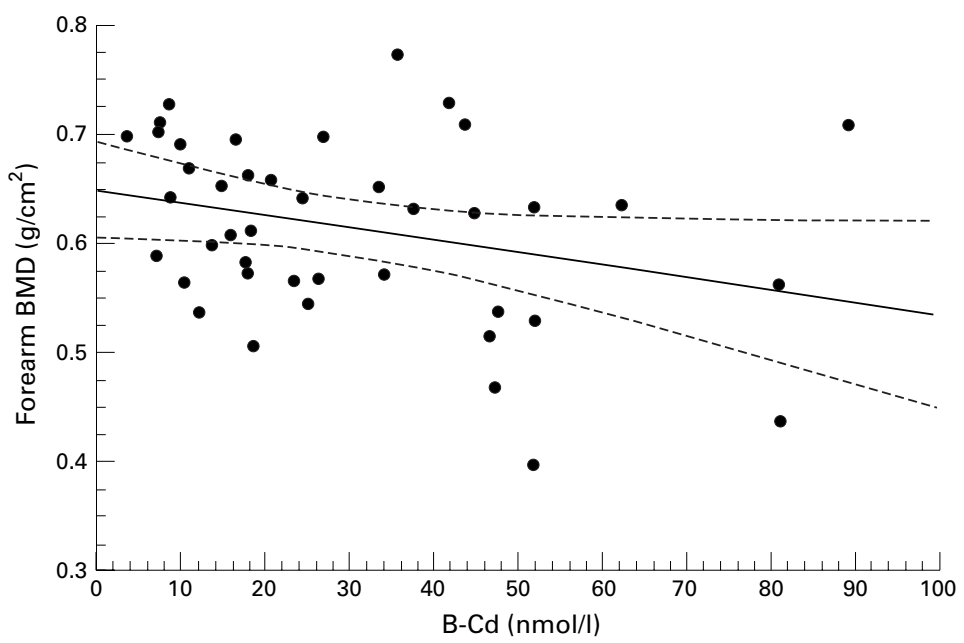

Figure 3 Forearm bone mineral density as a function of $B-C d$ in workers exposed to cadmium.

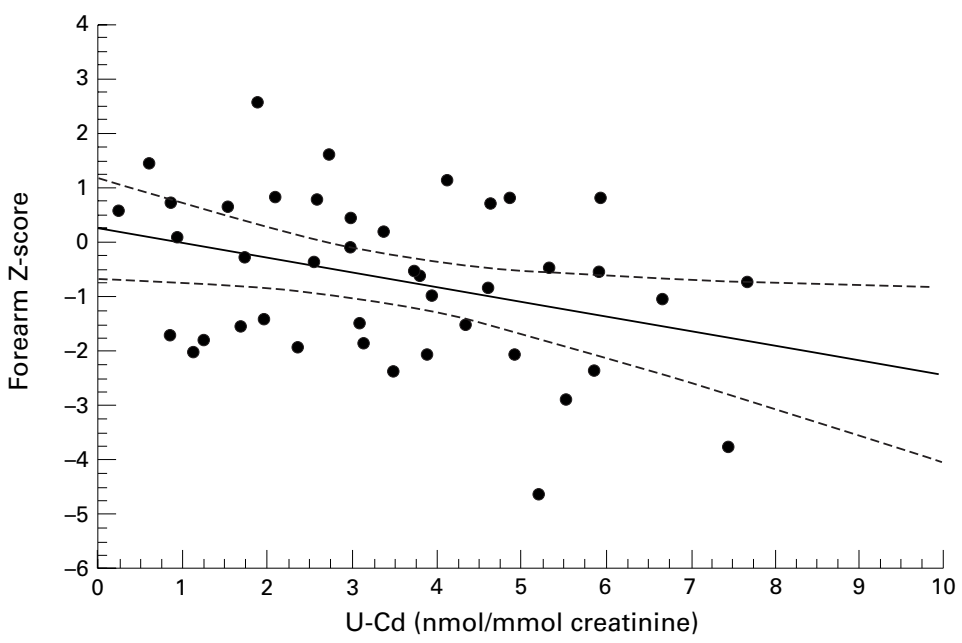

Figure 4 Forearm $Z$ score as a function of $U-C d$ in workers exposed to cadmium.

Hospital in Lund. The samples $(0.50 \mathrm{ml}$ blood $)$ were diluted 10 -fold with a solution containing EDTA $(0.5 \mathrm{~g} / \mathrm{l})$, Triton-X100 (0.5 g/l) and ammonia $(5 \mathrm{ml} / \mathrm{l})$ in Millipore water, and $100 \mu \mathrm{l}$ of an internal standard solution, containing 50 ng indium, was added. Each sample was prepared in duplicate. The sample solutions were introduced into a spray chamber in a segmented flow mode, with the diluent as a carrier and rinsing fluid. The detection limit of this method was $0.01-0.04 \mu \mathrm{g} \mathrm{Cd} / 1$. The precision, calculated as the coefficient of variation for the duplicate measurements, was $5 \%$. The accuracy was checked by including commercial reference samples (Seronorm, Nycomed, Oslo, Norway) of lyophilised whole blood and urine in each analytical series.

Cadmium in urine (U-Cd) was measured in 1984 and 1993 at the Department of Occupational Medicine at Linköping University Hospital. $^{8}{ }^{9}$

Bone mineral density was measured with two different instruments. Forearm BMD was measured with an ambulant instrument (Osteometer DTX-200), whereas BMD of the forearm, lumbar spine, and hip (neck and trochanter) was measured with a hospital based instrument (Hologic QDR 4500). Both instruments use the dual energy $x$ ray absorptiometry (DXA) technique. The non-dominant arm was measured with the patient in a supine position. The internal variation was checked by daily calibration with a phantom. The BMD assessed by the stationary instrument was compared with a reference material provided by the instrument supplier ${ }^{10}$ and to a local reference material (Löfman O, personal communication). The BMD assessed by the movable instrument was compared with a reference population furnished by the instrument supplier, based on measurements performed on normal Danes, aged 20-88 years, who were healthy volunteers. Subjects included in the reference population did not have any previous or present diseases known to influence calcium metabolism. No restrictions were made on smoking or other lifestyle habits.

Age and sex standardised $\mathrm{Z}$ score values were computed according to the formula:

$\mathrm{Z}$ score $=\left(\mathrm{X}_{\mathrm{u}}-\mathrm{X}_{\mathrm{m}}\right) / \mathrm{SD}$

where $\mathrm{X}_{\mathrm{u}}=$ measured bone density, $\mathrm{X}_{\mathrm{m}}=$ group mean for the same age group, $\mathrm{SD}=$ standard deviation in the reference population.

A common definition of osteoporosis, $\mathrm{Z}$ score $<-2$ was used. ${ }^{11}$ Data on $\alpha_{1-}$ microglobulin and $\beta_{2}$-microglobulin from 1993 were used to assess the degree of renal tubular dysfunction. Data on the glomerular filtration rate (GFR) from 1993 were used to estimate the degree of glomerular dysfunction.

\section{STATISTICAL METHODS}

Data were analysed with standard statistical methods, $t$ test for the comparison of means, and multiple regression for the multivariate analyses.

UNITS

Cadmium in blood is given in nmol/1 $(1 \mu \mathrm{g} / \mathrm{l}=$ $8.9 \mathrm{nmol} / \mathrm{l}$ ) and cadmium in urine is given in $\mathrm{nmol} / \mathrm{mmol}$ creatinine. $\beta_{2}$-Microglobulin in urine is shown as $\mu \mathrm{g} / \mathrm{mmol}$ creatinine $(1 \mu \mathrm{g} / \mathrm{g}$ creatinine $=0.112 \mu \mathrm{g} / \mathrm{mmol}$ creatinine $)$. 
Table 1 Determinants of forearm bone mineral density in workers exposed to cadmium, with blood cadmium (B-Cd) as a dose estimate of exposure to cadmium

\begin{tabular}{lll}
\hline Regression variable & Coefficient & p Value \\
\hline Age & -0.005 & 0.002 \\
B-Cd & -0.002 & 0.040 \\
Sex & -0.041 & 0.535 \\
Weight & 0.001 & 0.168 \\
Smoking & -0.010 & 0.374 \\
$\beta_{2}$-Microglobulin (1993) & 0.000008 & 0.297 \\
$\alpha_{1}-$ Microglobulin (1993) & 0.0006 & 0.266 \\
Glomerular filtration rate (1993) & -0.0010 & 0.196 \\
\hline
\end{tabular}

Table 2 Determinants of forearm bone mineral density in workers exposed to cadmium, with urinary cadmium (U-Cd) as a dose estimate of exposure to cadmium

\begin{tabular}{lll}
\hline Regression variable & Coefficient & p Value \\
\hline Age & -0.005 & 0.004 \\
U-Cd & -0.02 & 0.052 \\
Sex & -0.03 & 0.699 \\
Weight & 0.002 & 0.158 \\
Smoking & -0.09 & 0.476 \\
$\beta_{2}$-Microglobulin (1993) & -0.000002 & 0.927 \\
$\alpha_{1}$-Microglobulin (1993) & 0.0007 & 0.278 \\
Glomerular filtration rate (1993) & -0.0006 & 0.417 \\
\hline
\end{tabular}

\section{Results}

There was a good correlation between forearm BMD measured with the DTX 200 and the Hologic QDR 4500 (fig 1). As the hospital based instrument was considered superior, we used the measurements obtained from the Hologic QDR 4500 for the further analyses.

There was a good correlation between B-Cd estimated in 1996 and the 1993 estimates of U-Cd (fig 2). One worker (marked with an unfilled circle, fig 2) had an extremely pronounced tubular proteinuria and was excluded from the analyses in which U-Cd was used as the dose estimate.

The mean forearm $\mathrm{Z}$ score was significantly decreased in the group exposed to cadmium. The mean $\mathrm{Z}$ score value was -0.60 (95\% confidence interval $(95 \% \mathrm{CI})-1.08$ to -0.12$)$. The mean $\mathrm{Z}$ score for the spine was -0.47 ( $95 \%$ CI -0.92 to -0.03 ), for the hip neck -0.40 (95\% CI -0.75 to -0.05$)$ and for the hip trochanter $-0.22(95 \%$ CI -0.52 to -0.07).

A dose-effect relation was suggested between $\mathrm{B}-\mathrm{Cd}$ and forearm BMD (fig 3). No doseeffect relations were found for the spine or hip. A dose-effect relation was also suggested between U-Cd and Z score (fig 4). To account for the influence of age, sex, and other known or suspected risk factors (weight, smoking, and renal dysfunction) on BMD, a multiple

Table 3 Dose-response relation between blood cadmium $(B-C d)$ and prevalence of osteoporosis (Z score <-2) in workers exposed to cadmium

\begin{tabular}{llllll}
\hline $\begin{array}{l}\text { B-Cd,group } \\
(\text { nmolll) }\end{array}$ & $\begin{array}{l}\text { B-Cd,mean } \\
(\text { nmoll/ })\end{array}$ & $\begin{array}{l}\text { Cumulative } \\
\text { exposure } \\
\left(\mathrm{mg} / \mathrm{m}^{3} \cdot y\right)\end{array}$ & $\begin{array}{l}\text { Total } \\
\text { subjects }(n)\end{array}$ & $\begin{array}{l}\text { Subjects with } \\
\text { osteoporosis } \\
(Z \text { score }<-2.0)\end{array}$ & Prevalence (\%) \\
\hline$<40$ & 18 & 2.0 & 30 & 1 & 3.3 \\
$\geqslant 40$ & 57 & 4.7 & 13 & 6 & 46.2 \\
\hline
\end{tabular}

Table 4 Dose-response relation between urinary cadmium $(U-C d)$ and prevalence of osteoporosis ( $Z$ score $<-2)$ in workers exposed to cadmium

\begin{tabular}{lllll}
\hline $\begin{array}{l}\text { U-Cd group } \\
\text { (nmol/mmol } \\
\text { creatinine) }\end{array}$ & $\begin{array}{l}\text { U-Cd mean } \\
\text { (nmol/mmol } \\
\text { creatinine) }\end{array}$ & $\begin{array}{l}\text { Total subjects } \\
(n)\end{array}$ & $\begin{array}{l}\text { Subjects with } \\
\text { osteoporosis } \\
(Z \text { score<-2.0) }\end{array}$ & Prevalence (\%) \\
\hline$<5$ & 2.7 & 33 & 3 & 9.1 \\
$\geqslant 5$ & 7.4 & 10 & 4 & 40.0 \\
\hline
\end{tabular}

regression analysis was performed including age and other relevant variables. Tables 1 and 2 show the results.

We then divided the group of workers into two subgroups according to their cadmium dose. There was a suggested dose-response relation between $\mathrm{B}-\mathrm{Cd}$ and osteoporosis (defined as $Z$ score $<-2.0$, table 3. Note that the $\mathrm{Z}$ score is adjusted for age and sex. Further corrections for age should thus not be made). Table 4 shows a similar relation between U-Cd and osteoporosis.

The subgroup with tubular proteinuria (defined as $\alpha_{1}$-microglobulin $>1 \mathrm{mg} / \mathrm{mmol}$ creatinine) had a lower $Z$ score than the subgroup without tubular proteinuria $(\mathrm{p}=0.072)$.

\section{Discussion}

We have previously shown that B-Cd is a good dose estimate several years after the end of exposure. ${ }^{9}$ When tubular damage has occurred, B-Cd is a better dose estimate than $\mathrm{U}-\mathrm{Cd}$, as the kidney damage leads to a higher excretion of cadmium in urine. The current concentrations of blood cadmium were considerably lower than those found shortly after the excessive workroom exposure to cadmium at the end of the 1970s. ${ }^{12}$ Likewise, urinary excretion of cadmium has decreased, on average, by at least $57 \%$ since exposure ended. ${ }^{9}$ Thus, recently measured B-Cd values cannot readily be used for comparisons with other groups with current exposure to cadmium, or those having another exposure history. There is, however, a close linear correlation between the recent B-Cd data (1996) and previous U-Cd data (1984 and 1993). A B-Cd in 1996 of about $40 \mathrm{nmol} / 1$ corresponds to a U-Cd excretion around $5 \mathrm{nmol} / \mathrm{mmol}$ creatinine in 1993 (fig 2).

Two different instruments were used to measure BMD, a movable instrument (Osteometer DTX-200), and a stationary hospital based instrument (Hologic QDR 4500). There are several different techniques available for assessing BMD, the most common being based on $x$ ray films. Present measuring techniques based on $x$ ray films have a precision in vivo of $1.5 \%$ or better. Both the stationary hospital based instrument and the movable one are claimed to have a precision of $<1 \%$. The movable instrument is currently being used in a large population based study on environmental exposures and the risk for osteoporosis. Thus, it was of great importance to validate the movable instrument against an established hospital based one. The BMD values resulting from the DTX-200 measurements were 15\% lower than the values obtained with the Hologic QDR 4500 , which may be due to slightly different measuring positions. The regression coefficient (1.048) indicates, however, a very good agreement between the instruments and it was concluded that the DTX 200 showed valid forearm BMD data and can be used with confidence in other studies.

Since the discovery of itai-itai disease in the 1950s it has been recognised that very high cadmium exposure can lead to osteoporosis or 
osteomalacia. Only a few cases of bone disorders have been reported outside the cadmium polluted areas in Japan. Japanese studies show decreased BMD at B-Cd concentrations of the order of $100 \mathrm{nmol} / 1 .^{13}$

Animal experiments have shown that bone resorption due to cadmium exposure can occur at B-Cd concentrations similar to those reported for people occupationally exposed to cadmium and for people who smoke cigarettes (27-80 nmol/l). Moreover, these bone effects may occur early before the development of tubular damage.

The present findings indicated a decreased BMD in workers exposed to cadmium at lower concentrations of B-Cd (mean 29.3, range $3.5-89.4 \mathrm{nmol} / \mathrm{l}$ ) than previously noted in humans, but in accordance with the experimental findings in animals.

There was a suggested dose-effect relation between B-Cd and BMD, as well as between $\mathrm{U}-\mathrm{Cd}$ and BMD, significant at the $95 \%$ level, when other risk factors were included in the regression model. As expected, age was the most important determinant of BMD. Weight had a positive, but non-significant, regression coefficient in accordance with previous findings. ${ }^{14}$

The discrepancy found between different parts of the skeleton (low BMD in the forearm, normal in spine and hip) is not unusual. Although post-menopausal osteoporosis and cortisone induced osteoporosis initially dominate in trabecular bone, bone loss due to hyperparathyroidism and senile osteoporosis, for example, is most marked in the cortical bone of the forearm. It should be noted that forearm $\mathrm{BMD}$ is a good predictor of fractures, regardless of location.

We defined a subgroup of highly exposed people, with a cut off point for B-Cd of 40 $\mathrm{nmol} / \mathrm{l}$, which is above the 90 th percentile among non-occupationally exposed smokers in Sweden $(30 \mathrm{nmol} / \mathrm{l}),{ }^{15}$ but considerably below the B-Cd concentrations found in patients with itai-itai $(100-400 \mathrm{nmol} / \mathrm{l}) .{ }^{13}$ With U-Cd as the dose estimate, it should be noted that a 1993 $\mathrm{U}-\mathrm{Cd}$ value of $5 \mathrm{nmol} / \mathrm{mmol}$ creatinine corresponded roughly to a $1984 \mathrm{U}-\mathrm{Cd}$ value of 10 $\mathrm{nmol} / \mathrm{mmol}$ creatinine, which is the health based limit of the World Health Organisation. Thus, regardless of whether cadmium in blood or urine was used for estimating the cadmium dose, signs of osteoporosis occurred at lower cadmium concentrations than previously anticipated.

Furthermore, the definition of osteoporosis is debated and various measures have been used. Although osteoporosis in women has been defined as BMD $>2.5 \mathrm{SD}$ below the normal mean of a young adult healthy woman, ${ }^{16}$ there is no corresponding definition for men as yet. A BMD of one SD below the mean for a particular age is commonly applied ( $Z$ score $<-1.0) .{ }^{17}$ Another, more strict definition of osteoporosis ( $Z$ score $<-2$ ) has also been suggested. ${ }^{11}$ This definition was chosen in the present study to characterise cases with marked osteoporosis. Table 2 shows that there was a suggested dose-response relation between dose of cadmium and the prevalence of pronounced osteoporosis.

Other potential risk factors for osteoporosis include nutritional and lifestyle factors, decreased oestrogen concentrations, and smoking. ${ }^{18}$ Our study did not find any significant associations between smoking and BMD. Oestrogen concentrations were not included, as only two of the workers were women and both were premenopausal (39 and 40 years old). Nutritional factors were not investigated, but should not differ significantly from the reference population.

Few environmental causes of osteoporosis have been studied and apart from cadmium, other metals such as lead and aluminium have been discussed. ${ }^{19}$ The present study group were not known to be exposed to other metals to any extent.

In Japan, examination of people environmentally exposed to cadmium have shown an association between renal tubular dysfunction ( $\beta_{2}$-microglobulinuria) and decreased BMD in women but not in men. ${ }^{3} \beta_{2}$-Microglobulin was not measured in the present study, but as cadmium induced tubular lesions are irreversible we used the 1993 data. $^{8}$ There was no significant association between urinary $\beta_{2}$ microglobulin and BMD in this predominantly male group, which accords with the Japanese findings. The subgroup with tubular proteinuria $\left(\alpha_{1}\right.$-microglobulinuria) had a lower BMD than the group without tubular proteinuria, supporting the theory that cadmium may affect the bone mineralisation through the kidneys.

One possible link between cadmium accumulation in the kidney and bone demineralisation may be through a decreased renal activation of vitamin $\mathrm{D}$ to calcitriol. Reports from two of the areas of Japan polluted by cadmium show significant associations between renal damage induced by cadmium in the form of $B_{2}$-microglobulinuria, or increased serum creatinine, and lowered plasma concentrations of calcitriol. ${ }^{45}$

\section{Conclusion}

There was a suggested dose-effect relation between cadmium dose and bone mineral density. Furthermore, there was a suggested doseresponse relation between cadmium dose and osteoporosis. Although the present study population is small, the findings indicate that cadmium may cause bone demineralisation at a lower dose of cadmium than was previously anticipated.

\footnotetext{
This study was supported by a grant from the Swedish Council for Work Life Research. We thank Ann-Christin Palmqvist, Inger Ross, and Ann-Kristin Thunberg for valuable and skilful assistance in measuring BMD.

1 Kido T, Nogawa K, Yamada Y, et al. Osteopenia in inhabitants with renal dysfunction induced by exposure to environmental cadmium. Int Arch Occup Environ Health 1989;61:271-6.

2 Kjellström T. Mechanism and epidemiology of bone effects of cadmium [review]. IARC Sci Publ 1992;118:301-10.

3 Kido T, Nogawa K, Honda R, et al. The association between Kido T, Nogawa K, Honda R, et al. The association between cadmium-exposed subjects. Environ Res 1990;51:71-82.

4 Aoshima K, Kasuya M. Preliminary study on serum levels of 1,25 -dihydroxyvitamin D and 25-hydroxyvitamin D in cadmium-induced renal tubular dysfunction. Toxicol Lett 1991;57:91-9.
} 
5 Tsuritani I, Honda R, Ishizaki M, et al. Impairment of vitamin D metabolism due to environmental cadmium exposure, and possible relevance to sex-related differences in vulnerability to the bone damage. $\mathcal{F}$ Toxicol Environ Health 199

6 Kazantzis G. Renal tubular dysfunction and abnormalities of calcium metabolism in cadmium workers. Environ Health Perspect 1979;28:155-9.

7 Bhattacharyya MH, Sacco-Gibson NA, Peterson DP. Cadmium-induced bone loss: increased susceptibility in female beagles after ovariectomy. IARC Sci Publ 1992;118: 279-86.

8 Järup L, Persson B, Elinder CG. Decrased glomerular filtration rate in solderers exposed to cadmium. Occup Environ Med 1995;52:818-22.

9 Järup L, Persson B, Elinder CG. Blood cadmium as an indicator of dose in a long term follow-up of workers previously exposed to cadmium. Scand f Work Environ Health exposed to cad

10 Favus MJ. Bone density reference data. In: Favus MJ, ed. Primer on the metabolic bone disease and disorders of bone minPrimer on the metabolic bone disease and disorders of bone min
eral metabolism, 3rd ed. New York: Raven, 1996;463-5.

11 Stein MS, Packham DK, Ebeling PR, et al. Prevalence and risk factors for osteopenia in dialysis patients. Am $\mathcal{F}$ Kidney Dis 1996;28:515-22.
12 Elinder CG, Edling C, Lindberg E, et al. Assessment of renal function in workers previously exposed to cadmium. $\mathrm{Br} \mathcal{F}$ function in workers previo

13 Nogawa K, Kido T. Biological monitoring of cadmium exposure in itai-itai disease epidemiology [review]. Int Arch Occup Environ Health 1993;65:S43-6.

14 Krüger $\mathrm{H}$, Tuppurainen $\mathrm{M}$, Honkanen $\mathrm{R}$, et al. Bone mineral density and risk factors for osteoporosis-a population based study of 1600 perimenopausal women. Calcif Tissue Int 1994;55:1-7.

15 Friberg L, Elinder CG, Kjellström T, et al. Cadmium and Health: a toxicological and epidemiological appraisal. Boca Raton, FL: 1985;1:159-60.

16 Kanis JA, Melton LJ, Christiansen C, et al. The diagnosis of osteoporosis. F Bone Miner Res 1994;9:1137-41.

17 World Health Organisation. Assessment of fracture risk and its application to screening for postmenopausal osteoporosis. Geneva: WHO, 1994. (WHO Technical Report Series 843.)

18 Johnell O. Advances in osteoporosis: better identification of risk factors can reduce morbidity and mortality [review]. $\mathcal{f}$ risk factors can reduce morbidity

19 Goyer RA, Epstein S, Bhattacharyya M, et al. Environmental risk factors for osteoporosis. Environ Health Perspect 1994;102:390-4.

\section{Vancouver style}

All manuscripts submitted to Occup Environ Med should conform to the uniform requirements for manuscripts submitted to biomedical journals (known as the Vancouver style.)

Occup Environ Med, together with many other international biomedical journals, has agreed to accept articles prepared in accordance with the Vancouver style. The style (described in full in the $f A M A[1]$ ) is intended to standardise requirements for authors, and is the same as in this issue.

References should be numbered consecutively in the order in which they are first mentioned in the text by Arabic numerals on the line in square brackets on each occasion the reference is cited (Manson[1] confirmed other reports[2][3][4][5]). In future references to papers submitted to Occup Environ Med should include: the names of all authors if there are three or less or, if there are more, the first three followed by et al; the title of journal articles or book chapters; the titles of journals abbreviated according to the style of Index Medicus; and the first and final page numbers of the article or chapter. Titles not in Index Medicus should be given in full.

Examples of common forms of references are:

1 International Committee of Medical Journal Editors. Uniform requirements for manuscripts submitted to biomed journals. $\mathscr{F} A M A$ 1993;269:2282-6.

2 Soter NA, Wasserman SI, Austen KF. Cold urticaria: release into the circulation of histmaine and eosinophil chemotactic factor of anaphylaxis during cold challenge. $N$ Engl F Med 1976;294:687-90.

3 Weinstein L, Swartz MN. Pathogenic properties of invading micro-organisms. In: Sodeman WA Jr, Sodeman WA, eds. Pathologic physiology, mechanisms of disease. Philadelphia: W B Saunders, 1974:457-72. 